\title{
O imaginário entre fronteiras da educação e da religião
}

\author{
The imaginary between the boundaries of education and religion
}

\author{
Amauri Carlos Ferreira* \\ Vânia Noronha*
}

\begin{abstract}
Resumo
O objetivo desse artigo é discutir as contribuições da teoria do imaginário na constituição do sujeito individual e coletivo tendo como diálogo aspectos que se referem à educação e religião. Para tal, compreende que essas áreas são fundamentais na formação do homo symbolicus, que expressa pela linguagem, sua maneira de estar no mundo. $\mathrm{O}$ artigo ao discutir a crise do paradigma clássico apresenta a complexidade do emergente com base nas categorias analíticas presentes nesse aporte teórico, a saber: representação, mito, imagens entre outras. Com base nessas categorias estabelece-se um diálogo transdisciplinar entre os saberes que tem como ponto crucial o campo diverso do simbólico. É o simbólico que nos permite compreender as fronteiras entre as dimensões religiosas e as práticas sociais entendidas como educativas, materializadas na cultura de diversos modos. Conclui-se que a epistheme proporcionada pela teoria do imaginário é potente para pensarmos o diálogo intercultural e a superação do paradigma disciplinar presente em algumas práticas culturais, principalmente as educacionais e religiosas.
\end{abstract}

Palavras-chave: Imaginário. Religião. Educação. Entre Saberes. Fronteiras.

\begin{abstract}
The goal of this paper is to discuss the contributions of the theory of the Imaginary in the composition of the individual and collective subject considering educational and religious aspects. We understand that these areas are fundamental in the formation of the homo symbolicus, which uses language to express its way of being in the world. By discussing the crisis of the classical paradigm, we present the complexity of the emerging based on the analytical categories of this theoretical frame, namely: representation, myth, images, among others. These categories allow a transdisciplinary dialogue among fields of knowledge having as a crucial aspect the diverse field of the symbolic. Through the symbolic, we can understand the boundaries between the religious dimensions and the social practices, understood as educational, materialized in culture in various ways. We conclude that the episteme provided by the theory of the Imaginary is powerful for thinking about the intercultural dialogue and overcoming the disciplinary paradigm present in some cultural practices, especially educational and religious ones.
\end{abstract}

Keywords: Imaginary. Religion. Education. Fields. Boundaries.

\footnotetext{
Artigo recebido em 08 de fevereiro de 2017 e aprovado em 30 de março de 2017.

* Pós-doutor em Educação (UFMG), Doutor (UMESP) e Mestre em Ciências da Religião (PUC-SP), Professor de Filosofia no ISTA e nos Programas de Pós-Graduação em Educação e Ensino da PUC Minas. País de Origem: Brasil. E-mail: mitolog@pucminas.br.

* Doutora (USP) e Mestre em Educação (UFMG). Docente do Programa de Pós-Graduação em Educação e dos cursos de Educação Física e Pedagogia da PUC Minas. País de Origem: Brasil. E-mail: vaninhanoronha@gmail.com.
} 
A realidade, porém, é que o nosso pensamento - como toda a entidade viva - nasce para se vestir de fronteiras. Essa invenção é uma espécie de vício de arquitetura: não há infinito sem linha do horizonte.[...]. A verdade é esta: a vida tem fome de fronteiras. Podemos reaprender a criar fronteiras permeáveis. (Mia Couto).

\section{Introdução}

Há uma complexidade de estudos sobre o imaginário tendo em vista as várias bases epistemológicas nas quais ele se ancora. Suas teorias foram compondo cenários que apresentam, por vezes, grande dificuldade de compreensão e investigação. Ao longo do século XX, vários autores fizeram reflexões em torno dessa temática de forma complementar e também oposta. Fundamentam a teoria os escritos de Gaston Bachelard, Michel Mafessolli, Gilbert Durand, Sigmund Freud, Jaques Lacan, Cornelius Castoriadis, Henri Corbin, Jean-Jacques Wunerburger, Alberto F. Araújo. Destacam-se, no Brasil, José Carlos de Paula Carvalho, Maria Cecília S. Teixeira, Maria do Rosário S. Porto, Danielle de P. R. Pitta, Iduína M. B. Chaves, João de Deus V. Barros, dentre outros. Essas fundamentações foram suficientes para tornar o imaginário investigável e permitiram a sua compreensão para além do que o senso comum e algumas teorias o entendem, a saber, como fictício e irreal.

O século XX evidenciou aspectos do imaginário tendo em vista o avanço de pesquisas em torno das imagens, o que tornou impossível não o investigar. $\mathrm{Na}$ complexidade desses estudos, a imagem passa a ser considerada uma de suas manifestações e é compreendida, nesta teoria, como símbolo com base nos estudos de um dos seus maiores expoentes, o francês Gilbert Durand¹.

\footnotetext{
${ }^{1} \mathrm{O}$ pensamento de Gilbert Durand tem sua herança, no que se refere a problemática do imaginário, em dois autores: Gaston Bachelard e Carl Gustav Jung. Do primeiro, retoma a questão do simbolismo imaginário; do segundo, a noção de arquétipo. Chamamos atenção para este segundo autor tendo em vista a sua participação em 1966, no Círculo de Eranos (no mesmo período em que ele fundou o Centro de Pesquisas sobre Imaginário), que agregou, de forma interdisciplinar, autores de diversas áreas do saber humano. Sua fundadora, Olga Froebe-Kapteyn, mostrava interesse pela filosofia esotérica e pela teosofia. As discussões do Círculo de Eranos surgido em 1933 - perduram até a atualidade e são marcadas pela luta contra o espírito racional como forma de compensar a unilateralidade da razão. $O$ objetivo principal de Eranos sempre foi o de compensar a unilateralidade do racionalismo pela abordagem do simbólico. Mediante pesquisas interdisciplinares, seu intuito visa aproximar a relação da cultura oriental e ocidental, de forma a compreendê-las num elo que demarca o ser humano e sua dimensão simbólica (FERREIRA; SILVEIRA, 2015, p.2). Há nos autores participantes deste Círculo interesse voltado para "uma hermenêutica das imagens dos símbolos, do sagrado e dos mitos no imaginário das culturas" (WUNENBURGUER, 2003, p.13).
} 
Uma das preocupações desse autor é superar a lógica cartesiana, explicativa, linear e arbitrária para o símbolo, propondo a compreensão da sua ambivalência e busca por um método que "viabilize a apreensão, compreensão e interpretação dos motivos simbólicos em sua complexidade” (DIB, 2002, p. 2). Para isso, Durand (2004), em seus escritos sobre o imaginário e os modos de aprendê-lo, tece importantes análises sobre a desmitologização ocorrida no pensamento europeu e ocidental que, ao se tornar cientificista e racionalista, desvalorizou ontologicamente o imaginário e psicologicamente a função da imaginação.

Segundo o autor, foi a civilização da imagem que permitiu aos fenômenos históricos imaginados serem percebidos como reais, uma vez que, na história do pensamento, esses fenômenos eram considerados como invenção, fantasia, sonhos, alucinação, ora vinculados à faculdade de imaginar, ora a criações da imaginação. A imagem era considerada "produto de uma casa de loucos" (DURAND, 2004a, p. 13), pois, num universo mecânico, a arte de persuadir dos pregadores, dos poetas e dos pintores, jamais teria o acesso à dignidade de uma arte de demonstrar. Dessa forma, a abordagem poética cedeu lugar ao conhecimento determinista constituído pela experiência perceptiva e pelo raciocínio. Na contramão desse conhecimento, Durand desenvolve os estudos do imaginário e busca desvelar sua complexidade a partir do pensamento simbólico, de tal maneira que o imaginário hospeda o simbólico.

Ao identificarmos a educação e a religião, portadoras de um sistema forte de utilização de imagens como símbolo e como práticas simbólicas, porque sociais, consideramos ser o imaginário um potente referencial teórico para entendermos suas fronteiras na formação do sujeito individual e coletivo. Como bem nos diz José Carlos de Paula Carvalho (1990, p. 27), todas as práticas sociais são sempre simbólicas, uma vez que são manifestações de um universo imaginário numa práxis, por intermédio de um sistema sociocultural e de suas instituições.

Para ampliarmos nosso olhar sobre esses sujeitos (individual e coletivo) e aproximarmo-nos da complexidade da teoria do imaginário e sua articulação 
fronteiriça com a educação e a religião, estabelecemos como objetivo deste artigo compreender de que maneira ele (o imaginário), ao atravessar o mundo contemporâneo, aponta para sua morada, tendo a imagem como uma representação do símbolo que se abre para esse diálogo; e, ainda, identificar sua presença nesses dois campos do conhecimento.

\section{A morada do imaginário}

Em seus estudos, Amauri C. Ferreira (2002, p.24) afirma que "torna-se complexo, para maior parte dos estudiosos, investigar o imaginário como objeto de pesquisa devido à constituição de elementos/imagens que organizam um dever ser para o sujeito". Essa complexidade se dá ainda na definição do que vem a ser o imaginário. Para Durand (2002), o imaginário "é o conjunto das imagens e relações de imagens que constitui o capital pensado do homo sapiens - aparece-nos como o grande denominador fundamental, aonde se vêm encontrar todas as criações do pensamento humano" (p. 18). A partir desta argumentação, o autor afirma que o mundo não é natural, ele é humano. Não é dado ao homem, e sim representado.

Ruiz (2003) afirma que essa representação produz o simbólico e possibilita que o "ser humano, antes de pensar logicamente as coisas, imagina-as", de modo que "os objetos passam de elementos sem sentido a ser coisas com significado" (p. 48). A representação só pode existir na forma de linguagem, pois "qualquer imagem do mundo está sempre impregnada de uma significação particular” (p.193).

Para Durand (2002), essa representação, ou seja, o imaginário, produz-se no trajeto antropológico que consiste na

incessante troca ao nível do imaginário entre as pulsões subjetivas e assimiladoras e as intimações objetivas que emanam do meio cósmico e social. [...] Há uma gênese recíproca que oscila do gesto pulsional ao meio ambiente material e social, e vice-versa. É nesse intervalo, neste caminhamento reversível que se deve instalar a investigação antropológica. (DURAND, 2002, p. 41). 
Em outras palavras, trajeto antropológico é o produto da articulação entre o biopsíquico e o sociocultural, o subjetivo e o objetivo, que permite ao homem realizar a sutura epistemológica entre Natureza e Cultura, mediada pelo símbolo e, ainda, construir seus aparelhos simbólicos (PAULA CARVALHO, 1990).

Essas representações estabelecem o modo como elas se modificam no que se refere ao trânsito das identidades dos sujeitos que as compõem, estabelecendo para o imaginário uma íntima relação com a cultura. Para Paula Carvalho (1990), a cultura é sempre tingida pelo imaginário e funciona como ponte entre os polos das formas estruturantes, isto é, do que é instituído - patente (códigos, formações discursivas e sistemas de ação) - e o do plasma existencial - latente (das coisas do espírito, das vivências, dos espaços, da afetividade e do afetual).

Para esse autor, na intermediação da cultura identificamos os transdutores híbridos que são como encruzilhadas nas quais se engendram o sentido da ação e da existência de qualquer grupo. São eles, os transdutores híbridos, que nos permitem afirmar que a educação e a religião (entendida na sua pluralidade) se manifestam nessa dupla articulação (patente/latente), podendo, de acordo com a situação, ser mais vivenciada num polo do que em outro, sem que, com isso, deixem de ser elas mesmas.

O imaginário não é nem mera criação individual, nem simples produção social, ele articula o polo biopsíquico com o sociocultural, expressando tanto as invariâncias arquetipais, como as variações das configurações socioculturais. Nesse sentido, o imaginário se manifesta nos dois polos, mas é produzido no circuito entre eles, ou seja, na confluência do subjetivo e do objetivo, do pessoal e do meio sociocultural (TEIXEIRA, 2001).

Para Wunenburguer e Araújo (2003), o imaginário não é apenas um termo que designa um conglomerado de imagens heteróclitas, mas remete a uma esfera psíquica na qual estas adquirem forma e sentido devido a sua natureza simbólica. O imaginário de cada indivíduo está enraizado numa bio-história pessoal (diz de seu 
temperamento, caráter, estrutura pulsional, fantasias) que é levada a expandir-se, a renovar-se por meio de processos de simbolização que o fazem participar na totalidade do mundo. Para esses autores, o imaginário individual se inscreve e se apoia no imaginário coletivo, que o alimenta e renova a si próprio por ocasião das obras individuais, constituindo uma gramática simbólica, de imagens primordiais ou arquetípicas. Cada imaginário cultural consiste numa configuração retirada da totalidade das imagens possíveis, obedecendo a uma estrutura funcional universal.

Essa construção, sendo percebida como integrante de processos identitários fixos, enrijece o que é da ordem de sua flexibilidade. Tal perspectiva é muito comum em estudos de fenômenos religiosos e educacionais que postulam uma única forma de manifestação do imaginário. Desconstruir essa ideia e compreender a formação de imagens no campo do simbólico é fundamental; para tal, torna-se necessário perceber no mundo da cultura como as representações foram se sedimentando.

O ser humano, sapiens-demens (Morin), confere sentido ao mundo pela mediação do simbólico (homo symbolicus), que transita pelos níveis do consciente e do inconsciente, do objetivo e do subjetivo, da razão e da imaginação. Esse simbolismo é constitutivo do processo de individuação do ser, pela equilibração do Sinn (sentido) e Bild (forma), ou seja, a consciência clara (em parte coletiva, formada por conduta, métodos, línguas inculcadas na psique pela educação) e o inconsciente coletivo (libido) (DURAND, 1988).

Ruiz (2003) defende que a principal característica do imaginário, esse semfundo humano, é a criação. Para esse autor, o imaginário, assim como o humano, é paradoxal, pois emerge com força criativa, mas só pode existir na forma de identidade delimitada. Ele é indeterminável, entretanto, sua concretização só se dá a partir da imaginação determinada. 
A imaginação é, para Durand (2002), o dinamismo organizador, fator de homogeneidade na representação. Comungando com a crítica de Bachelard à etimologia, Durand (2002) afirma ser a imaginação

potência dinâmica que "deforma" as cópias pragmáticas fornecidas pela percepção e esse dinamismo reformador das sensações torna-se o fundamento de toda a vida psíquica porque as leis da representação são homogêneas, a representação sendo metafórica a todos os seus níveis, e, uma vez que tudo é metafórico, ao nível da representação todas as metáforas se equivalem. (DURAND, 2002, p. 30).

Assim, a imaginação é "dinamicamente negação vital, negação do nada da morte e do tempo" (DURAND, 1988, p. 99). Em outras palavras, sua principal função é permitir que o homem encontre meios de enfrentar a angústia original do tempo que passa e da consciência da morte em sua certeza única.

No cerne etimológico do imaginário coloca-se a imagem que, para Durand (2002, p. 29), é "portadora de um sentido que não deve ser procurado fora da significação imaginária”. De forma literária, o autor afirma que "as imagens não valem pelas raízes libidinosas que escondem, mas pelas flores poéticas e míticas que revelam" (idem).

Na constituição do imaginário, Durand adota o método de convergência para mostrar as vastas constelações de imagens que se constituem pelos símbolos. São constelações praticamente constantes e parecem estruturadas por certo isomorfismo dos símbolos convergentes. Segundo ele, os símbolos constelam porque são desenvolvidos de um mesmo tema arquetipal, são variações de um mesmo arquétipo e constituem os conjuntos simbólicos. Na verdade, há uma atração (ou um polo atrator) entre as imagens arquetípicas que as constituem constelações. São esses conjuntos, ou essas constelações, em que as imagens convergem em torno de núcleos organizadores, que a arquetipologia antropológica vem tentando distinguir nas manifestações humanas da imaginação, também em seus aspectos educacionais e religiosos. 
Para estabelecer o princípio de classificação das constelações de imagens, Durand comunga com a intuição bachelardiana, para a qual as metáforas axiomáticas indicam o movimento. A reflexologia, por meio dos conjuntos sensório-motores mais arcaicos, constitutivos dos sistemas de "acomodações" elementares e originários, fornece pistas para entendermos como as dominantes reflexas atuam e intervêm nos processos de assimilação constitutivos do simbolismo. Assim, concorda Danielle da Rocha Pitta (2005) que as imagens não vêm prontas e transmitidas pela hereditariedade. Elas se formam pela interação dos reflexos e das pulsões, às quais estão ligadas com o meio material e social.

As matrizes originárias, nas quais vão se constituir os grandes conjuntos simbólicos, são definidas por Durand (2002) a partir de três grandes séries de gestos dominantes: a postural, a de nutrição e a copulativa. A primeira é aquela que coordena ou inibe todos os outros reflexos, quando se coloca o corpo de um bebê em pé. Essa dominante faz com que a verticalidade e a horizontalidade sejam privilegiadas e que toda perturbação da postura provoque um reflexo postural dominante. Por sua vez, a dominante de nutrição se manifesta nos recém-nascidos pelo reflexo de sucção labial e de orientação adequada da cabeça; ela pode ser considerada como um princípio de organização, como uma estrutura sensóriomotora. Por fim, a dominante copulativa, a do acasalamento que traduz a pulsão sexual, ou o próprio ato sexual. Para alguns autores, são organizações inatas que dependem da erotização do sistema nervoso.

Durand (baseando-se nos estudos de Leroi-Gurhan, 1943) mostra como que esses três grandes gestos, dados pela reflexologia, desenrolam-se e orientam a representação simbólica, pois "cada gesto implica ao mesmo tempo uma matéria e uma técnica, suscita um material imaginário e, senão um instrumento, pelo menos, um utensílio" (DURAND, 2002, p. 54).

Apesar de esse esquema contar com três estruturas, Durand (2002) classifica-as em dois regimes, um diurno e um noturno. O regime diurno é estruturado a partir da dominante postural e se identifica com a tecnologia das 
armas, a sociologia do soberano mago e guerreiro, os rituais de elevação e de purificação. As armas, as flechas e os gládios seriam símbolos frequentes. Por outro lado, o regime noturno compreende as dominantes digestiva e cíclica, e supõe as técnicas do continente e do habitat, os utensílios continentes como as taças e os cofres, os valores alimentares e digestivos, a sociologia matriarcal e alimentadora, as técnicas do ciclo, do calendário agrícola e da indústria têxtil, os símbolos naturais ou artificiais do retorno, a roda, a cruz, os mitos e os dramas astrobiológicos.

O imaginário é o dinamismo equilibrador, que se apresenta como a tensão entre as duas "forças de coesão" desses regimes, cada uma relacionando as imagens em dois universos antagonistas - o heroico e o místico - que se acomodam, no estado médio e normal da atividade psíquica, em outro universo: o dramático. Nele, as imagens antagonistas conservam a sua individualidade, a sua potencialidade, e só se reúnem no tempo, na linha narrativa, num sistema, e não, propriamente, numa síntese. (DURAND, 1988)

Durand ainda nos deixa pista para melhor compreendermos a dinâmica intrínseca e o uso de conceitos sobre a teoria do imaginário. Esclarece que os três reflexos dominantes se prolongam em esquemas (schémes), entendidos como generalização dinâmica e afetiva da imagem, que constituem a factividade e não a substantividade geral do imaginário e fazem a junção entre os gestos inconscientes da sensório-motricidade, entre as dominantes reflexas e as representações. São esses esquemas que formam o esqueleto dinâmico, o esboço funcional da imaginação. Os esquemas se diferem dos gestos reflexológicos, porque já não são engramas teóricos, e sim, trajetos encarnados em representações concretas. Durand exemplifica: ao gesto postural correspondem dois esquemas, o da verticalização ascendente e o da divisão visual e manual; ao gesto do engolimento correspondem o esquema da descida e o acocoramento na intimidade (p. 60). 
Esses gestos diferenciados em esquemas, em contato com o meio ambiente e social, para Durand, determinam os grandes arquétipos, no sentido junguiano², e sua importância é estabelecer o ponto de junção entre o imaginário e os processos racionais.

Durand afirma que a falta de ambivalência do arquétipo, sua universalidade constante e sua adequação ao esquema são o que o diferencia do símbolo. Um mesmo arquétipo pode se ligar a imagens muito diferentes nas culturas e, vários esquemas podem, nela, imbricar. O arquétipo está no nível da ideia e da substantificação, enquanto o símbolo é substantivo e nomeia. No prolongamento dos esquemas, arquétipos e símbolos encontra-se o mito, que, para Durand, é o grande articulador entre esquemas, arquétipos e símbolos uma vez que é

um sistema dinâmico de símbolos, arquétipos e esquemas, sistema dinâmico que, sob o impulso de um esquema, tende a compor-se em narrativa. O mito é já um esboço de racionalização, dado que utiliza o fio do discurso no qual os símbolos se resolvem em palavras e os arquétipos em idéias. O mito explicita um esquema ou um grupo de esquemas. (DURAND, 2002, p. 63).

O mito, para Durand, promove a doutrina religiosa, o sistema filosófico, a narrativa histórica, e sua organização se constitui, também, numa constelação de imagens. Durand concorda com Jung sobre as imagens arquetipais, que estão na base das teorias científicas que, para eles, são as mesmas que inspiram contos e lendas.

É este isoformismo dos esquemas, arquétipos e símbolos, presentes no seio dos sistemas míticos e, também, das constelações estáticas, que permite verificar a existência de certos protocolos normativos de representações imaginárias, bem

\footnotetext{
${ }^{2}$ Para Jung (2002), os arquétipos são as imagens primordiais. São formas mentais cuja presença não encontra explicação na vida dos indivíduos, mas são como formas primitivas e inatas que representam uma herança do espírito humano. É uma tendência instintiva que pode se manifestar como fantasias e revelar a sua presença apenas por imagens simbólicas. Os arquétipos são o "estádio preliminar, a zona matricial das ideias" (DURAND, 2002, p. 61), que não exercem primazia sobre as imagens. A ideia seria o comprometimento pragmático do arquétipo imaginário, num contexto histórico e epistemológico dado. Jung já dizia que os arquétipos são "porções da própria vida", imagens ligadas ao indivíduo, por meio de uma "ponte de emoções"; daí ser impossível dar a ele uma interpretação arbitrária. $O$ arquétipo, segundo Jung em Durand, precisa ser explicado de acordo com as condições totais de vida do indivíduo, ao qual se relaciona (idem, p. 96).
} 
definidos e, relativamente, estáveis, agrupados em torno dos esquemas originais, que Durand (2002) denomina de estruturas. Dito de outro modo, as estruturas são como uma forma transformável, que desempenham o papel de protocolo motivador, para todo um agrupamento de imagens. A própria estrutura está suscetível de se agrupar em outra, mais geral, que são os regimes.

Assim, no regime diurno, cuja dominante é a postural, o enfrentamento do “monstro devorador” se dá pelo combate ou pela fuga. As imagens são polarizadas em torno de símbolos teriomorfos (animalidade agressiva), nictomorfos (trevas terrificantes) e catamorfos (queda assustadora). Os esquemas são os de ascensão, de separação e do arquétipo da luz. Esses símbolos correspondem à estrutura esquizomorfa ou heroica (separar) que possui como noção básica, a potência. Colocam sempre, em confronto, os contrários e possuem como princípios lógicos, a explicação, a justificação e a exclusão (DURAND, 2002).

O regime noturno compreende duas estruturas: a mística ou antifrásica (confundir) e a sintética ou dramática (ligar). A primeira tem a ver com as dominantes digestivas, nas quais a fase trágica do tempo é minimizada ou eufemizada pela negação. As noções básicas são: a analogia e a similitude. A segunda busca a harmonização dos contrários, sendo a noção básica a de causalidade, principalmente, nas formas final e eficiente (idem).

Durand está convencido de que é a circulação do mito que define e descreve uma sociedade; portanto, é o imaginário, a matriz das práticas simbólicas de um conjunto social. Encontraremos tantos mitos, quanto existirem culturas, pois as representações não são homogêneas. Mesmo no interior de culturas diversas, será possível encontrarmos, em diferentes momentos e épocas, diferentes mitos, em superposição, em atualização, ou mesmo adormecidos, obrigados a permanecerem na sombra, mas capazes de, a qualquer momento, serem potencializados. Para Durand vivemos o tempo da ressurgência do mito, isto é, verdadeiramente de um regresso, pois não há mitos novos e esses não são muitos, uma vez que se ligam aos 
arquétipos, esses também em número limitado.

O autor identifica a presença de três níveis míticos, que atuam em conjunto em nossa sociedade, na atualidade. O primeiro refere-se à pedagogia e ainda é do século XIX, prometeica, positivista e fragmentada, que se preocupa mais com os resultados, do que com os processos educacionais; o segundo é o do mass media, da televisão, do cinema. Este nível mítico representa o minuto de libertação dos sujeitos, frente à pedagogia, uma vez que não é pensado e preparado por professores, ou pedagogos e, portanto, permite certo erotismo e certa anomia. Em outras palavras, cultivam os mitos dionisíacos e órficos. Mas o próprio Durand (2004b) denuncia as imagens "enlatada[s]" (p. 18) que vêm sendo veiculadas pelas mídias, que paralisam, anestesiam e transformam o espectador, quase sempre os trabalhadores, em consumidores passivos, não só de produtos como de ideologias. O terceiro nível mítico é o dos sábios, dos investigadores que constroem novas mitologias e reconhecem nelas o seu poder e eficácia.

São constatações como estas que permitiram a Durand (2004) elaborar o conceito de bacia semântica, na qual o imaginário de uma sociedade segue um percurso semelhante ao curso de um rio. Na bacia semântica, pode-se observar uma sucessão de seis fases: o escoamento, a divisão das águas, as confluências, o nome do rio, a organização dos rios e os deltas e meandros. Esse conceito nos ajuda a entender como se dá a saturação de um mito e o prenúncio de novos e nos permite afirmar que estamos (con)vivendo, nesse início de século e milênio, com a crise da modernidade e a revolução paradigmática e epistemológica, numa “zona de alta pressão imaginária” (DURAND, 2004b, p. 7).

O autor diz que nos encontramos, atualmente, em ressonância com o tema do retorno do mito e das problemáticas sobre as visões do mundo, gravitando ao redor do símbolo, ou do que ele denomina "galáxia do imaginário", donde se desdobra o mais profundo pensamento contemporâneo. Por isso, torna-se cada vez mais atual uma discussão sobre o imaginário na vida da humanidade. 


\section{Diálogos entre fronteiras com o imaginário: Religião e Educação}

Contrapondo com o modelo cientificista presente em nossa sociedade, consideramos ter trazido elementos teóricos para compreender que "é por meio do imaginário que nos reconhecemos como humanos, conhecemos o outro e apreendemos a realidade múltipla do mundo" (TEIXEIRA; ARÁUJO, 2013, p.77). Para que a construção do imaginário se efetive e se coloque entre as fronteiras, a religião e a educação são formas de pensar que se complementam e ordenam na cultura, um modo de ser e estar no mundo. No entanto, estas áreas como várias outras encontram-se em situação de crise.

No cenário global atual, muito provavelmente, a palavra mais ouvida por todos nós tem sido "crise" e ela se materializa em seus âmbitos individual e coletivo, por vezes concreta e ainda inventada. São crises de todas as ordens e naturezas: pessoais, de caráter, histéricas, imaginárias, midiática, política, educacional, econômica, religiosa, planetária. Edgar Morin (2002) afirma que o ser humano é um ser crísico, incompleto, contraditatorial e plural. Se por um lado a crise é vista como algo difícil de superar, trabalhosa, desestabilizadora, por outro, ela retira sujeitos e coletividades do lugar e exige um deslocamento, uma busca de solução, o reequilíbrio e, por isso mesmo, ela é positiva.

Este lado positivo da crise, ou de retorno às coisas, coaduna com o pensamento de Hannah Arendt quando diz que esse tempo "nos obriga a voltar às questões mesmas e exige respostas novas ou velhas, mas de qualquer modo julgamentos diretos" (1992, p.223). Tal perspectiva abre possibilidades para perceber que novas formas de compreensão do real se fazem necessárias. No que se refere aos modelos para o campo do imaginário, a desestabilização não é somente positiva, mas também esclarecedora, principalmente para áreas de formação humana de longo prazo como a religião e a educação. É nas fronteiras do imaginário que estas áreas se encontram tendo em vista a relação entre saberes por elas sedimentadas ao longo do tempo. 
As abordagens de cunho inter e multidisciplinares têm apontado para a necessidade de compreensão do imaginário como sendo estruturante no modo de perceber fenômenos educacionais e religiosos. Tal perspectiva conduz para a afirmação de Durand para quem "a multidisciplinaridade é um acesso entre saberes indispensável ao progresso das disciplinas individuais. Aqui vamos um pouco mais longe: constatamos que a interdisciplinaridade inicia uma transdisciplinaridade" (DURAND, 1996, p.242).

$\mathrm{O}$ aspecto interdisciplinar destas áreas, ao fomentar a transdisciplinaridade, tem contribuído para uma compreensão essencial do imaginário educacional e religioso. Tal abordagem se iniciou nos anos de 1930 numa tentativa de romper com o paradigma tradicional e estabelecer uma relação possível entre os saberes. É interessante lembrar que o movimento interdisciplinar surgiu na segunda metade do século XX, a partir da década de 60. Ivani Fazenda (2006) aponta para as três etapas deste movimento aqui destacados por Ferreira e Senra (2012):

Na década de 1970, fez-se a construção da nova epistemologia interdisciplinar. Foi um período de conceituação básica, marcada pela preocupação terminológica. Nos anos 1980, em sua segunda etapa desenvolveu-se a explicitação das contradições epistemológicas decorrentes dessa construção e buscou-se uma diretriz sociológica e metodológica para a interdisciplinaridade. A terceira etapa já nos anos de 1990, pode-se falar da construção de uma nova epistemologia interdisciplinar de um projeto antropológico e de uma teorização. (FERREIRA; SENRA, 2012, p.261).

É importante destacar que este movimento a favor da interdisciplinaridade tem a participação de autores que faziam parte do Centro de Estudos do Imaginário, dentre eles Morin e Georges Gusdorf. Esse último, elaborou juntamente com outros autores um projeto sobre a interdisciplinaridade e as Ciências Humanas, que se tornou um dos documentos mais importantes sobre a temática. (GUSDORF, 1967).

É nesse trajeto interdisciplinar que estas áreas sedimentam seu encontro, e também por volta da segunda metade do século XX, nos anos de 1960, que esta 
ideia de um diálogo entre religiões pode ocorrer. Tal iniciativa se deu no âmbito da Igreja Católica nos anos de 1962 a 1965, ao propor a interlocução do catolicismo com as quatro grandes expressões religiosas, a saber: judaísmo, islamismo, hinduísmo e budismo; para depois buscar o diálogo com religiões tradicionais africanas e as ameríndias na América. Se este diálogo ocorre e como, não é nosso objetivo aqui discutir. O dado que nos chama atenção é que esta tentativa interdisciplinar exige uma nova postura que o paradigma dominante não consegue resolver, nem no campo da teoria e nem da prática.

Não é demais lembrar que a principal consequência dos efeitos do paradigma dominante foi a dissociação entre o mundo da cultura humanista e o da científica. Entretanto, ao provocar a dissociação, o próprio paradigma criou a possibilidade de uma dialógica em que o conflito entre os termos antagonistas o tornou produtor e criador, modificando-o, ao interferir no domínio das ideias e do sentimento, instaurando um novo paradigma. Este paradigma emergente Morin define como da complexidade -segundo ele, é uma problemática ainda marginal no pensamento científico, epistemológico e filosófico (2000, p.175) -, ela [a complexidade] é um obstáculo, um desafio, uma motivação para o pensar.

O autor nos alerta que a complexidade não é o vocábulo mestre, que tudo explica; é, antes, a palavra despertadora que nos impulsiona para explorarmos o inexplorado. O pensamento complexo é aquele que "patrulha no nevoeiro, o incerto, o confuso, o indizível, o indecisível” (MORIN, 2001, p. 179-180), o indecifrável. É um convite a um diálogo com os mistérios do mundo. Assim, a complexidade não deve ser confundida com a completude do conhecimento que apresenta receitas e respostas prontas. Ao contrário, o princípio que a rege é a incompletude, a incerteza. O desafio posto para as ciências é o de encontrar um método que saiba distinguir, sem separar e dissociar, promovendo uma comunicação do que é distinto. Isso exigirá um conhecimento multidimensional, que considere o homem em suas dimensões biológicas e sociais e, ao mesmo tempo, um outro olhar sobre a cultura. 
Paula Carvalho (1990, p. 22) denomina o paradigma da complexidade como holonômico e afirma que este se caracteriza por analisar a cotidianidade oximorônica, numa rede de equivalência, com uma razão aberta, evolutiva, residual, complexa, parareflexiva, en-ciclo-pédica (trans e meta disciplinar), dialógica. Afirma que - ao contrário do paradigma clássico para o qual a ontologia é dualista/dicotômica, a epistemologia objetiva/analítica, a metodologia empírica, a causalidade determinista, a análise redutiva e a dinâmica entrópica - o paradigma emergente é monista/pluralista, subjetivo/interativo, fenomenológico/ analógico, teleonômico/probabilisto, metafísico/estrutural, nulentrópico/negentrópico.

Como a educação e a religião estão interligadas na teoria e no método em perspectivas inter, multi, pluri, transdisciplinares, na complexidade, no campo do imaginário, elas possuem elementos comuns que se interpenetram em uma formação do indivíduo que repetem seus princípios. Com este não lugar no campo disciplinar, marcado por outras abordagens e aberto a novas perspectivas, o imaginário exige aprofundamentos e investigações dialógicos. Talvez seja esse o maior ganho com a crise de modelos na tradição contemporânea, tendo em vista que o imaginário não configura uma disciplina e o seu lugar está hospedado no "entre saberes". Tal abordagem explica a complexidade do próprio termo imaginário, pois ele não se encontra em modelos predeterminados, como são as áreas do saber lógico e racional. Durand (1996) contribui ao afirmar que "o imaginário não é uma disciplina, mas um tecido conjuntivo entre as disciplinas, o reflexo - ou a reflexão? que acrescenta ao banal significante e significados, o apelo do sentido" (p. 231).

No campo religioso, o apelo para o sentido, nos estudos sobre o imaginário, aponta para a imagem/representação que se constitui no âmbito das religiões específicas. Tal abordagem levou Ferreira (2002) a afirmar que "a formação de imagens que se sedimentam no universo simbólico do sujeito depende de materialidades que vão modulando maneiras individuais e coletivas" (FERREIRA, 
2002, p.83). Essa materialidade se constitui, numa primeira perspectiva, uma unidade mítica geradora de valor, na qual as imagens se conformam e criam um imaginário mítico/religioso que, para desmitificá-lo, é necessário fazer uma desconstrução também de longa duração. Tal situação se repete ao longo do tempo tendo em vista o poder da imagem. A sua relação com o mito, na perspectiva de formação, leva-nos a refletir a religião como sendo um pensar por imagens.

Perseguir as imagens foi o objetivo dos estudos de Vânia F. Noronha Alves (2008) quando analisou o mito da Grande-Mãe, presente na manifestação do Reinado de Nossa Senhora do Rosário, considerada pelos negros sua mãe e protetora. Com base na narrativa mítica, que funda esse catolicismo negro e inventado, o estudo pôs em relevo as imagens míticas que o mito evoca, investigando as modulações presentes no seu imaginário. A autora identificou a manifestação religiosa dedicada à essa Santa e aos Santos Pretos considerando suas festas enquanto estruturas simbólicas complexas, reatualizadoras do mito e constituintes de uma importante dimensão da vida coletiva, que diz de nós mesmos e das relações que se estabelecem entre o sagrado, a ancestralidade, o simbólico, a história, as práticas educativas, dentre outros.

Esses estudos, dentre tantos outros, permitem-nos afirmar que "o mito designa uma história verdadeira e preciosa, porque sagrada, exemplar e significativa" (ELIADE, 2006). Ao fornecer modelos para o comportamento humano ele confere significado e valor à existência. São as narrativas que nos permitem concordar com Mircea Eliade (2006) quando diz que conhecendo o mito conhece-se a origem das coisas.

Dentro da estrutura do imaginário, a composição dessas narrativas exerce um fascínio para os estudiosos. Jaques Le Goff (1994) as entendia dentro de uma trama que tinha por composição a representação, o simbólico e as imagens ${ }^{3}$.

\footnotetext{
${ }^{3}$ Para Le Goff estes termos ajudam a compor a trama do imaginário: a representação engloba todas e quaisquer traduções mentais de uma realidade exterior percebida. Está ligada a abstração. O simbólico em sua urdidura só pode ser concebido quando o objeto considerado é remetido para um sistema de valores subjacentes, histórico ou ideal. As imagens revelam-se no decorrer de uma simples observação. São concretas e constituem o objeto da iconografia (LE GOFF,1994).
} 
Hilário Franco Junior (1998), nesta mesma direção, estabelece para a compreensão desta trama três modalidades que se entrelaçam, a saber, o mito, a ideologia e a utopia4.

Entendemos que, para o campo do imaginário religioso, o caráter de representação ganha força tendo em vista que os outros elementos que o constituem são formados a partir da educação, ou melhor dizendo, das práticas educativas, que a complementam mediante esse pensar por imagens. Daí que

A representação do real é compreendida através de imagens que foram constituídas mediante o sentido conferido às coisas...O imaginário permite entender representações coletivas que a sociedade produz, uma vez que os significados atribuídos ao real entrelaçam-se com as estruturas simbólicas. (FERREIRA, 2002, p.29).

Como vimos, para entender o imaginário religioso e sua expressão é necessário compreender sua sustentação ideológica, que se constitui com base no mito e em seus sistemas religiosos. Para tal, o entendimento do imaginário religioso requer por parte dos pesquisadores estabelecer categorias analíticas que expressem a origem e a extensão de fenômenos religiosos. Ferreira (1995 e 2002), em seus estudos sobre religião e cidade, estabelece três categorias analíticas consideradas por ele centrais para a análise de fenômenos religiosos: mito, rito e utopia5. O autor aponta para a construção do imaginário religioso entendendo-o como sendo os "projetos religiosos de instituições que, de forma imperativa, acionam o vetor de imagens-representações na mente dos sujeitos que as internalizam" (FERREIRA, 2002, p. 38). Tal perspectiva reproduz no mundo dos

\footnotetext{
${ }^{4} \mathrm{O}$ mito foca sua atenção em um passado indefinido para explicar o presente. A ideologia projeta no futuro as experiências históricas do grupo - e idealizadas, passadas e presentes. A utopia parte do presente na tentativa de antecipar ou preparar um futuro que é a recuperação de um passado idealizado (FRANCO JUNIOR, 1998).

${ }^{5} \mathrm{~A}$ tríade mito, rito e utopia foi trabalhada pelo autor em sua dissertação de mestrado e tese de doutorado.Na dissertação o autor examinou o fenômeno religioso de uma cidade do interior de Minas Gerais. O trabalho buscou, por meio da análise das aparições de Nossa Senhora na vila mineira de Piedade dos Gerais, compreender a construção do sujeito religioso, individual e coletivo, em um contexto mítico, ritualístico e utópico (FERREIRA,1995). Por sua vez, a tese de doutoramento objetivou compreender a formação do imaginário católico com base na experiência narradados sujeitos coletivos sobre seus modos de vida no mundo urbano. $O$ autor utiliza essas três categorias analíticas como centrais para compreender e interpretar a formação de imaginários epocais expressos em lugares e tempos da memória. Nessas categorias o mito é entendido como uma narrativa verdadeira, que remonta às origens; o rito como uma categoria intermediária que mobiliza o mito e o coloca em ação; e a utopia como um desejo humano voltado para o futuro com raízes no passado, que, apoiada em dois pilares, o símbolo e o desejo, ressuscita o concreto colocando fim a utopia abstrata (FERREIRA, 2002).
} 
indivíduos elementos/imagens da crença ou da fé que definem o seu modus vivendi. Para que ocorram estas internalizações no mundo do sujeito torna-se necessário a formação de outro imaginário, o educacional.

No campo educacional percebe-se que os estudos sobre imaginário e educação vêm ganhando cada vez mais força em nosso país, impulsionados pelos grupos de estudos, ainda em número reduzido, mas com produções de qualidade significativa, percebidas não só nas dissertações e teses, mas também nos eventos científicos e nas publicações.

As contribuições desses estudos vêm no sentido de superar a pedagogia do empanturramento de cérebros, denunciada por Gusdorf (1970), que Eliane Atihé (2008) tão bem nos relembra, e de ampliar o olhar sobre os sujeitos imaginantes. Para isso, a autora propõe, com base em James Hillman e outros, uma educação da alma. Diz ela:

uma educação para o cultivo da alma ocupa-se, mais que tudo, de cultivar sua própria alma, isto é, seu significado profundo, sua interioridade, seu fundo psicológico e mítico, enfim, a dimensão misteriosa e afetiva desse trabalho ambíguo, porque simultaneamente coesivo e diferenciador. (ATIHÉ, 2008, p. 67).

$\mathrm{Na}$ direção de uma educação da alma caberia à escola construir o conhecimento com base nas suas dimensões inter, pluri, multi e transdisciplinar num caminho que leve os sujeitos a viver suas emoções, devaneios, sonhos e fantasias. Nesse sentido, os conhecimentos advindos de todas as manifestações das artes, do lazer, das culturas, equivocadamente rotuladas como marginais, dos diferentes gêneros e etnias, que têm no corpo sua expressão, precisam ser consideradas e adentrar os muros e portões de nossas escolas, construindo uma outra pedagogia: a do imaginário.

Na tentativa de definir o que seria uma “pedagogia do imaginário”, Araújo e Araújo (2009, p. 63-64) lançam mão do pensamento de outros autores e consideram que essa seria: uma pedagogia oximorônica, hermesiana, mediada pela "coincidentia opositorium", uma vez que concilia conceitos e imagens (PAULA 
CARVALHO, 1998); uma pedagogia da escuta (PAULA CARVALHO, 1990); (os trabalhos desenvolvidos em Reggio Emilia); uma pedagogia do olhar que promova um exercício meditativo-hermenêutico e inspire-se em pintores, poetas, escritores, músicos, dentre outros, com o objetivo de recuperar a faculdade transmutativa do olhar de modo que esse torne-se novamente incandescente qual ótica imaginal, para apreender o invisível e o poder simbólico do mundo e da vida (RILKE, 2001); (MOTTANA, 2004); uma pedagogia sem hábitos e estereótipos, ousada e perturbadora de uma razão instituída; uma pedagogia que se inventa e que seja capaz de compreender o imaginário dos outros; uma pedagogia porta-voz dos deuses (POSTMAN, 2002 e HILLMAN, 1977); uma pedagogia como o processo pelo qual o imaginário conduz a vida das imagens, dando-lhes sentido ou uma inteligibilidade existencial; uma "didática da invenção" (BARROS, 1985, 1993, 1996, 2015).

No âmbito escolar esses autores concordam com Teixeira (2006) e atribuem como função de uma pedagogia do imaginário o estímulo à imaginação, por que imaginar é reconhecer-se. Caberia a escola e seus agentes a tarefa de ensinar ao aluno a poética do devaneio para melhor eufemizar o seu cotidiano e cultivar a sensibilidade e a afetividade como canais de abertura da imaginação em direção ao mundo (apud ARAÚJO; ARAÚJO, 2009, p. 64).

Sem dúvida alguma, as discussões sobre currículos, metodologias e avaliações precisam se apropriar desses conceitos e avançar, se realmente quisermos sair do lugar e construir elementos para a superação das crises aqui discutidas, com o propósito de construir um outro mundo, pois é sabido que é possível.

\section{Considerações Finais}

O campo de pesquisa do imaginário, por se apresentar como objeto de orientações epistemológicas diversas, traz para a educação e para a religião elementos de grande complexidade, tendo em vista que os estudos nessas áreas têm 
se constituído numa investigação interdisciplinar teórica e metodológica. O caminho do imaginário, ao apontar para uma perspectiva transdisciplinar, ou “entre saberes”, coloca em diálogo duas áreas que nos permitem discuti-las com base em aportes teóricos emergentes, no sentido de ampliar nossa compreensão sobre a formação dos sujeitos individual e coletivo. Nesse caso, torna-se ponto crucial para esse diálogo que seja considerado o campo diverso do simbólico, que compreende tanto as dimensões religiosas quanto as práticas sociais entendidas como educativas, ao apropriarem-se de conceitos de campos do conhecimento também emergentes. Dessa forma, o imaginário se abre para a constituição do eu em relação ao outro, mediado por essas duas dimensões, pela imagem, pela representação, pelo símbolo, pelos arquétipos, dentre outros.

No que se refere a formação identitária dos sujeitos, levantamos algumas indagações: De que maneira a formação a longo prazo do processo educativo e das religiões, no que se refere a suas ideologias, contribui para a formação dos sujeitos individual e coletivo, de modo a pensar o outro como diferente, a respeitá-lo e considerar seus símbolos? Como os processos educativos escolarizados podem e devem considerar o imaginário e suas práticas simbólicas nessa formação? É possível pensar com imagens na educação e na religião? Nessa perspectiva, como seria a construção do conhecimento e de seus processos de aprendizagens?

Tais indagações, a partir do que se entende por imaginário religioso e educacional em construção e formação, têm nos remetido a pensar que o diálogo entre esses campos na atualidade é possível, tendo em vista que o vetor que forma seus princípios ordenadores tem como matriz representações de unidades imperativas simbólicas. O imaginário torna-se potencial para pensarmos o diálogo intercultural e a superação do paradigma disciplinar que ainda impera em algumas práticas culturais, principalmente as educacionais. Vislumbramos assim que esse caminho de estudos ainda é um desafio para pesquisadores e educadores mas, ao mesmo tempo, apresenta-se fértil para pensarmos esse diálogo mediante a fundamentação da virtude da tolerância hospedada nestas áreas do conhecimento. 
Vislumbramos ainda a construção de uma educação onde a razão seja sensível e apaixonada.

Finalizamos com uma reflexão de Clarissa Pinkola Estés, poetisa e psicanalista junguiana, quando nos propõe pensar sobre o que seria esse racionalismo apaixonado na sua "Ciranda das mulheres sábias”:

Já houve quem dissesse que o racionalismo nunca é apaixonado, e que a paixão nunca é racional. A meu ver, isso está errado. Uma vida racional digna de ser vivida é profundamente apaixonada. Uma paixão digna de ser sentida tem meios racionais para se moldar bem e se manifestar na realidade consensual, trata-se de um processo conjunto, como o das raízes da árvore que fazem crescer a copa; e a copa da árvore que envia mensagens às raízes para que elas cresçam e se expandam também. (ESTÉS, 2007, p. 120).

\section{REFERÊNCIAS}

ALVES, Vânia Fátima Noronha. Os festejos do Reinado de Nossa Senhora do Rosário em Belo Horizonte/MG: práticas simbólicas e educativas. São Paulo. 2008. 252 p. Tese (Doutorado em Educação). Faculdade de Educação. Universidade de São Paulo.

ARAÚJO, Alberto Filipe; ARAÚJO, Joaquim Machado de. Imaginário educacional: figuras e formas. Niterói: Intertexto, 2009.

ARENDT, Hannah. Entre o Passado e o Futuro. São Paulo: Perspectiva, 1992.

ATIHÉ, Eliana Braga Aloia. A educação em busca da sua própria alma. In: BARROS, João de Deus V. (Org.). Imaginário e educação. Pesquisas e reflexões. São Luís: EDUFMA, 2008.

BARROS, Manoel de. Livro de pré-coisas. Rio de Janeiro e São Paulo: Record, 1985.

BARROS, Manoel de. Livro das ignorãças. Rio de Janeiro e São Paulo: Record, 1993.

BARROS, Manoel de. Livro sobre nada. Rio de Janeiro e São Paulo: Record, 1996.

BARROS, Manoel de. Menino do mato. Rio de Janeiro: Objetiva, 2015.

DIB, Marco Antonio. As propostas de Planos Nacionais de educação: um ensaio mitocrítico. São Paulo, 2002 Dissertação (Mestrado em Educação). Faculdade de Educação. Universidade de São Paulo.

DURAND, Gilbert. A imaginação simbólica. São Paulo: Cultrix/EDUSP, 1988.

DURAND, Gilbert. Campos do imaginário. Lisboa: Instituto Piaget, 1996. 
DURAND, Gilbert. O imaginário. Ensaio acerca das ciências e da filosofia da imagem. 3. ed. Rio de Janeiro: DIFEL, 2004a.

DURAND, Gilbert. O retorno do mito: introdução à mitodologia. Mitos e sociedades. In: Revista FAMECOS, Porto Alegre, n. 23, 2004b.

DURAND, Gilbert. As estruturas antropológicas do imaginário. $3^{\mathrm{a}}$ ed. São Paulo: Martins Fontes, 2002.

ELIADE, Mircea. Mito e realidade. 6. ed. São Paulo: Editora Perspectiva, 2006.

ESTÉS, Clarissa Pinkola. A ciranda das mulheres sábias. Ser jovem enquanto velha, velha enquanto jovem. Rio de Janeiro: Rocco, 2007.

FAZENDA, Ivani Catarina Arantes. Interdisciplinaridade, história, teoria e método. Campinas: Papirus, 2006.

FERREIRA, Amauri Carlos. As aparições em Piedade dos Gerais e a construção do sujeito religioso. São Paulo. 1995. Dissertação (Mestrado em Ciências da Religião). Pontifícia Universidade Católica de São Paulo.

FERREIRA, Amauri Carlos. O imaginário religioso e modos de vida urbana: experiência da juventude católica em Belo Horizonte-Minas Gerais, anos 80. São Paulo. 2002. Tese (Doutorado em Ciências da Religião). Universidade Metodista de São Paulo.

FERREIRA, Amauri Carlos; SENRA, Flávio. Tendência Interdisciplinar das Ciências da religião no Brasil. O Debate epistemológico em torno da interdisciplinaridade e o paralelo com a constituição da área no país. In: NUMEN - Revista de Estudos e pesquisa da religião, Juiz de Fora, v.15, n.2, p.249-269. Disponível em:

<https://numen.ufjf.emnuvens.com.br/numen/article/view/1729/o>. Acesso em: o7 jan. 2017.

FERREIRA, Amauri Carlos; SILVEIRA, Luiz Henrique. Do Círculo de Eranos à construção do simbólico, em Carl Gustav Jung.In: Revista de Psicologia, USP, São Paulo, v.26, n2, 2015. Disponível em: <http://www.scielo.br/scielo.php?script=sci_arttext\&pid=So10365642015000200259\&lng=en\&nrm=iso\&tlng=pt $>$. Acesso em: 07 jan. 2017.

FRANCO JUNIOR, Hilário. Cocanha: história de um país imaginário. São Paulo:

Companhia das Letras, 1998.

GUSDORF, Georges. Professores para quê? Lisboa: Moraes, 1970.

GUSDORF, Georges. Les sciences de l'homme sont des sciences humaines. Paris: Société d'Éditions les Belles Lettres, 1967.

HILlmAN, James. Le Mythe de la Psycanalyse. Trad. par Philippe Mikiriammos. Paris: Imago, 1977.

JUNG, Carl Gustav; VON FRANZ, Marie Louise; HENDERSON, Joseph L.; JAFFÉ, Aniela. O homem e seus símbolos. Rio de Janeiro: Nova Fronteira, 2002. 
LE GOFF, Jaques. O imaginário medieval. Lisboa: Editorial Estampa, 1994.

LEROI-GURHAN, André. Evolution et technique. I: L'homme er la Matière. A. Michel, Paris, 1943.

MIA COUTO. Repensar o pensamento redesenhando fronteiras. In: Cassiano Elek Machado (Org.). Pensar a Cultura. Porto Alegre: Arquipélago Editorial, 2003.

MORIN, Edgar. Ciência com consciência. 5. ed. Rio de Janeiro: Bertrand Brasil, 2000.

MORIN, Edgar. A cabeça bem-feita: repensar a reforma, reformar o pensamento. 5. ed. Rio de Janeiro: Bertrand Brasil, 2001.

MORIN, Edgar. O método IV. As idéias. 3. ed. Porto Alegre, RS: Editora Sulina, 2002.

MOTTANA, Paolo. La visione smeraldina: introduzione ala pedagogia immaginale. Milano: Mimesis, 2004.

PAULA CARVALHO, José Carlos. Antropologia das organizações e educação. Um ensaio holonômico. Rio de Janeiro: Imago Editora, 1990.

PAULA CARVALHO, José Carlos. Imaginário e mitodologia: hermenêutica dos simoblos e estórias de vida. Londrina: UEL, 1998.

PITTA, Danielle Perin Rocha. Iniciação à teoria do imaginário de Gilbert Durand. Rio de Janeiro: Editora Atlântica, 2005.

Rilke. Rainer Maria. Cartas a um jovem poeta. A canção de amor e de morte do portaestandarte Cristóvão Rilke. Trad. Paulo Rónai e Cecília Meireles. São Paulo: Globo, 2001.

RUIZ, Castor M. M. Bartolomé. Os paradoxos do imaginário. Sinos: Editora Unisinos, 2003.

TEIXEIRA, Maria Cecília Sanches. A dinâmica do imaginário e a trajetividade da cultura: re-significando o social. Conferência do Imaginário e das Representações Sociais da Educação Física, Esporte e Lazer, Laboratório do Imaginário e das Representações Sociais em Educação Física, Esporte e Lazer - LIRES/UGF, 2001. (mimeo).

TEIXEIRA, Maria Cecília Sanches. Pedagogia do Imaginário e função imaginante: redefinindo o sentido da educação. Revista Olhar do Professor, Ponta Grossa, 2006, v.9, n.2, p. 215-227.

TEIXEIRA, Maria Cecília Sanches; ARAÚJO, Alberto Filipe. Gilbert Durand: imaginário e educação.2. ed. Niterói: Intertexto, 2013.

WUNENBURGUER, Jean-Jacques; ARAÚJO, Alberto Filipe. Introdução ao imaginário. In: ARAÚJO, Alberto Filipe e BAPTISTA, Fernando Paulo (Coord.). Variações sobre o imaginário. Domínios, teorizações e práticas hermenêuticas. Lisboa: Instituto Piaget, 2003 . 